\title{
The function of stimulus meaning and ability level in discrimination learning
}

NORMAN R. ELLIS, UNIVERSITY OF ALABAMA

WALTER W. PORTER, SOUTHEAST MISSOURI STATE COLLEGE

Groups of Ss with high and low verbal skills performed on a rote learning task with meaningful and non-meaningful pictures as stimuli. An interaction effect was predicted in which highly verbal Ss differed little on the two tasks and low verbal Ss differed widely. Both main effects and the interaction were statistically significant.

It has been shown that pretraining in which $S$ learns distinct responses to stimuli will facilitate subsequent learning of a task which employs these same stimuli (e.g., see Pfafflin, 1960; Spiker \& Norcross, 1957). Several hypotheses have been advanced to account for this finding. Two of the more likely explanations are the attention-to-cues hypothesis of Hake \& Eriksen (1955), and Arnoult's (1957) contention that facilitation may result from learning labels which "fit" or are appropriate for the stimulus. The latter idea gains some support from the Pfafflin study. However, as Cantor (1965) shows, the isolation of the specific processes underlying performance in stimulus pretraining experiments is difficult.

Although the exact manner in which facilitation occurs is unknown, it seems clear that stimulus pretraining does facilitate learning. There is also evidence that delayed response performance is facilitated in a similar manner (Spiker, 1956). Stimulus pretraining proves effective with mentally retarded Ss on the delayed response task (Barnett, Ellis, \& Pryer, 1959) and with normal Ss on the discrimination learning task (Cantor, 1955; Smith \& Means, 1961).

In view of the fact that many studies show that learning names for stimuli facilitates performance on a transfer task, it would appear that learning, on some tasks, may depend jointly upon S's verbal skills and the verbal demands of the task. The present study provided information on this issue. A two-choice discrimination task employed familiar and non-familiar pictures as discriminanda, thus making differential verbal demands on these Ss. It was predicted that the $\mathrm{S}$ with the low verbal skill is severely handicapped on the verball demanding task.

\section{Method}

Subjects. The "high ability" Ss were 40 college sophomores and 4011 th and 12th grade students. The "low ability" Ss were 80 students from a state residential institution for dependent children.

It is reasonable to assume, on the basis of IQ scores as well as the general background of these Ss, that they differed markedly in verbal skills.

Apparatus. A $36 \mathrm{~mm}$ slide projector, a 25.5 in. $\times 19.5$ in. screen, slides, two response buttons, and electro- mechanical programming and recording devices constituted the apparatus. The screen was mounted in a wooden frame with response switches (push buttons) 3 in. above the upper edge and 3 in. below the lower edge and in the horizontal center of the screen. The projector was mounted out of S's view behind the screen. A reinforcement light cast a spot of green light on the screen. The 16 test slides (shown in Fig. 1) were drawings of familiar objects or complex geometric designs.

Procedure. The "high ability" Ss were assigned equally and without bias to two groups. The mean IQS of these groups were 117 (SD 10.9) and 120 (SD 10.4): Mean CAs were $240 \mathrm{mo}$. and $233 \mathrm{mo}$. The "low ability" group was similarly divided: mean IQs were 76 (SD 7.6) and 77 (SD 7.2): Mean CAs were 197 and 201 mo. The Ss received a practice session in which they learned the correct response (upper or lower button) to each of two slides which were both either familiar or nonfamiliar, depending upon S's group assignment. Sixteen slides, eight of each of two, were randomly arranged in the projector trays for this procedure. These practice presentations were repeated without interruption until $S$ met a criterion of six successive currect responses.

For the main task, $\mathrm{S}$ was required to learn responses to eight stimuli. Two trays, each containing 64 slides,

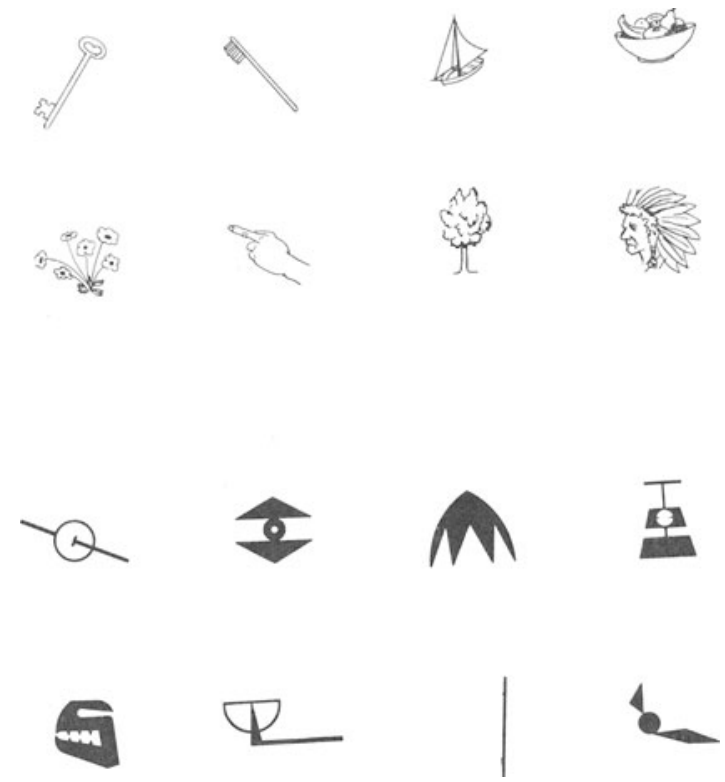

Fig. 1. The meaningful (top) and the nonmeaningful (bottom) stimuli. 
were used. Slides were randomly arranged in blocks of 16, eight pictures appearing twice in each block. The 64 slide series was repeated without interruption until $\mathrm{S}$ reached the criterion of 16 successive correct responses or had responded 1000 times. The task was S-paced, i.e., a stimulus remained on the screen until $\mathrm{S}$ responded. A correct response was followed immediately with the reinforcing light which was shown for about $.5 \mathrm{sec}$. (slide change time). A new stimulus was presented immediately following this $.5 \mathrm{sec}$. interval. Correct responses were assigned equally and randomly to top and bottom buttons with the restriction that a given button was not correct more than three times in succession.

\section{Results and Discussion}

A $t$ test demonstrated that there were no statistically significant differences between high school and college students constituting the high ability group on the learning task $(\% \mathrm{R}+)$. Therefore, these date received no further differential treatment.

The main findings are presented in Fig. 2, which shows per cent correct responses $(R+)$ for the four groups over 960 trials. Ss meeting the criterion are assumed to perform without error for the remainder of the 960 trials. An analysis of variance yielded an $\mathrm{F}$ of 28.62 ( $\mathrm{df}=1 / 156)$ for stimulus meaningfulness and an $\mathrm{F}$ of 35.18 (df $=1 / 156$ ) for ability level, both significant at the .001 level. The $\mathrm{F}$ of 10.85 (df $=$ 1/156) for interaction was significant at the .01 level . Further analysis with $t$ tests showed that only the

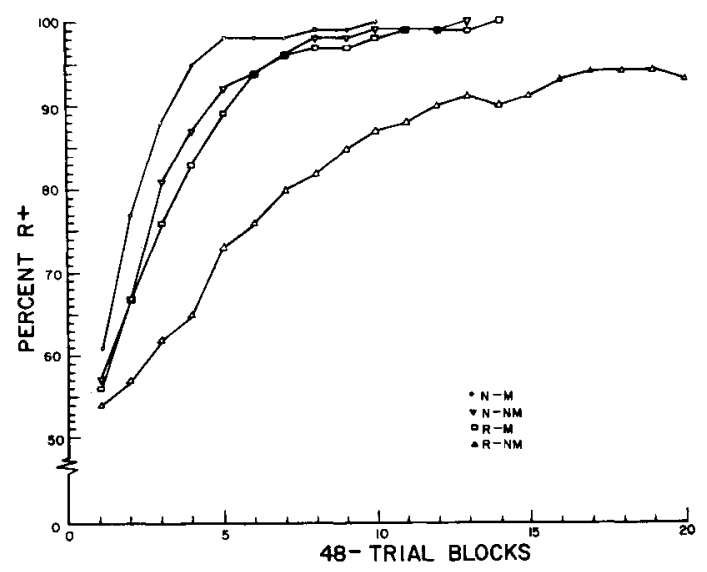

Fig. 2. Performance of the four groups over 960 trials. high ability non-meaningful and low ability meaningful groups failed to differ significantly.

Although Ss in the present study were not experimentally pretrained, it seems likely that past experience led to differences in "mediating" skills, probably consisting of verbal habits, which affected S's performance on these tasks. It is apparent that the performance of Ss of differing ability level, as defined by some index of intelligence, cannot be predicted without also taking into account task variables such as meaningfulness or familiarity of the discriminanda. This finding implies that individual differences in performance on a learning task may not only reflect absolute differences in capacity to form "associative connections," but also may result from differences in past experiences which relate to the formation of learning sets. Obviously, further research is needed to more clearly isolate the processes underlying these findings.

\section{References}

Amoult, M. D. Stimulus predifferentiation: Some generalizations and hypotheses. Psychol. Bull., 1957, 54, 339-350.

Bamett, C. D., Ellis, N. R., \& Pryer, Margaret w. Stimulus pretraining and the delayed reaction in defectives. Amer. J. ment. Defic., 1959, 63, 104-111.

Cantor, G. N. The effects of three types of pretraining on discrimination learning in preschool children. J. exp. Psychol., 1955, $49,399-342$.

Cantor, Joan H. Transfer of stimulus pretraining to motor pairedassociate and discrimination learning tasks. In L. P. Lipsitt \& C. C. Spiker (Eds.), Advances in child development and behavior. New York: Academic Press., 1965.

Hake, H. W., \& Eriksen, C. W. Effect of number of permissible response categories on learning of a constant number of visual stimuli. J. exp. Psychol., 1955, 50, 161-167.

Pfafflin, Shelia M. Stimulus meaning in stimulus predifferentiation. J. exp. Psychol., 1960, 59, 269-274.

Smith, M. P., \& Means, J. R. Effects of type of stimulus pretraining on discrimination learning in mentally retarded. Amer. J. ment. Defic., 1961, 66, 259-265.

Spiker, C. S. Stimulus pretraining and subsequent performance in the delayed reaction experiment. J. exp. Psychol., 1956, 52, 107-111.

Spiker, C. S., \& Norcross, Kathryn J. Effects of previously acquired names on discrimination performance. Child Develpm., $1962,33,859-864$.

\section{Note}

1. This research was supported by grants from the National Institute of Mental Health, Public Health Service, Grant Nos. M-4433 and $\mathrm{MH}$ 10724. The data in this study were collected at George Peabody College and Tennessee Preparatory School while the senior author was a faculty member at Peabody College and the second author was a graduate student. 